\title{
Digestive Functional Symptoms among Ground Employees in an Airline Company in Relation to Diet, Insomnia and Lifestyle Factors
}

\author{
Motoko Takaoka ${ }^{1}$, Torsten Lindgren ${ }^{2}$, Håkan Lundgren ${ }^{3} \&$ Dan Norbäck $^{2}$ \\ ${ }^{1}$ Department of Biosphere Sciences, School of Human Sciences, Kobe College, Kobe, Japan \\ ${ }^{2}$ Department of Medical Sciences, Uppsala University Hospital, SE-751 85 Uppsala, Sweden \\ ${ }^{3}$ Department of Occupational Health and Aviation Medicine (HMS), Scandinavian Airlines System (SAS), \\ SE-195 87 Stockholm, Sweden \\ Correspondence: Motoko Takaoka, Department of Biosphere Sciences, School of Human Sciences, Kobe \\ College, 4-1 Okadayama Nishinomiya 662-8505 Hyogo, Japan. Tel: 81-79-851-8423. E-mail: \\ takaoka@mail.kobe-c.ac.jp
}

Received: November 12, 2015 Accepted: January 7, 2016 Online Published: February 29, 2016

doi:10.5539/gjhs.v8n11p1

URL: http://dx.doi.org/10.5539/gjhs.v8n11p1

\begin{abstract}
Purpose: There are some epidemiological studies on pilots and cabin staff, but we found few health studies on aviation ground employees. The aim was to study associations between digestive symptoms in airline ground employees and diet, insomnia and lifestyle factors.

Methods: A standardized questionnaire was mailed to all Stockholm ground employees in a Scandinavian airline company, 201 service agents (ticketing and gate service) and 564 office workers from the same company participated. Associations were analysed by multiple logistic regression.

Results: Of the service agents, $13.8 \%$ reported poor appetite, $17.5 \% \%$ heartburn, $14.1 \%$, diarrhea, $51.7 \%$ bloating, $18.8 \%$ constipation and $15.40 \%$ epigastralgia. Service agents reported more bloating $(\mathrm{OR}=1.56$; $p<0.01)$, and poor appetite $(\mathrm{OR}=2.33 ; p<0.01)$ than office workers. The prevalence of insomnia was $77.7 \%$ among service agents and $63.1 \%$ among office workers $(p<0.001)$. In service agents, insomnia was related to poor appetite $(\mathrm{OR}=2.49 ; p<0.01)$, heartburn $(\mathrm{OR}=2.14 ; p<0.01)$, diarrhea $(\mathrm{OR}=3.62 ; p<0.001)$ bloating $(\mathrm{OR}=1.62 ; p<0.01)$, constipation $(\mathrm{OR}=2.74 ; p<0.01)$ and epigastralgia $(\mathrm{OR}=3.44 ; p<0.001)$. In office workers, there were no associations between insomnia and digestive symptoms. In the total material of ground employees $(\mathrm{N}=765)$, higher body mass index (BMI) was related to diarrhea and females suffered from more constipation and epigastralgia. Older age was related to heartburn and bloating. Smoking was related to poor appetite, more heartburn and epigastralgia and less constipation. The number of years employed at the airline company was negatively associated with heartburn, diarrhea and bloating. Frequent fast food consumption was associated with more bloating and heartburn. Frequent vegetables consumption was associated with less heartburn.
\end{abstract}

Conclusion: Insomnia and digestive symptoms were more common among service agents than office workers in the same airline company, possible partly due to stress. Besides insomnia, BMI, smoking, female gender, age, and diet were associated with digestive symptoms.

Keywords: airline ground employees, diet, digestive symptoms, fast food, insomnia, shift work, service agents

\section{Introduction}

The world's airlines' passenger traffic increased by $6.4 \%$ in 2011 on a $6.5 \%$ rise in capacity, according to ICAO (International Civil Aviation Organisation). The number of passengers has doubled every 12-15 year period since 1970s. Increased airframe and engine technology has improved efficiently in term of capability and economic performance (Upham, 2003). This development means reduction in cost per tickets and more people can afford to travel. Moreover, the globalization contributes to the increased air travel.

There are some epidemiological studies on health among pilots and cabin staff but we found few health studies on aviation ground staff. Aviation ground staff is divided in aircraft loaders, service agents (check-in staff or ramp agents) and office workers. One study concluded that the spectrum of disease seen among aviation ground personnel is not different from that seen in general occupational medicine clinics, except for low back pain 
which is more common in ground personnel (Froom et al., 1996). Another study investigated accidents among airport ground personnel and concluded that slips, trips and falls were the most common causes of accidents (Ribak et al., 1995). There is a difference in working schedules between ground staff and office workers in airline companies. Aircraft loaders and service agents are shift workers with early morning or late night work while most aviation office workers don't have shift work. Due to the increased financial competition between airlines, the pace of work increases and this development may lead to more medical problems. Another well-known problem is incidents of airline passenger misconduct ("unruly passengers") which can happen during flight but also on the ground (Pierson et al., 2007)

Digestive symptoms are common in the general population (Frexinos et al., 1998; Tougas et al., 1999). Stomach pain (Epigastralgia) (Ehinger, 2013a) and diarrhea (Schöldeen, 2015) can be caused by infections from viruses, bacteria or bacterial toxins, lactose intolerance and other food allergy. Heartburn with acid reflux (Campbell et al., 2010; Ehinger, 2014) can be caused by irregular sleep, irregular meal times, smoking, and consumption of alcohol, coffee or tea, especially late at night. In addition, subjects with a high body mass index (BMI) may have more heartburn (Fisher et al., 1999). Constipation can occur if food contains too little fiber, low consumption of water, low degree of physical activity, anxiety and stress, and certain medications (Ehinger, 2013b). Bloating can be caused by swallowing air while eating or drinking or smoking, and after consumption of certain food products such as beans, cabbage and onions (Ehinger, 2013c). Food allergies and lactose intolerance can give digestive symptoms (Ehinger, 2013c; Campbell et al., 2010). Moreover, occupational stress is a common cause of gastrointestinal alterations (Huerta-Franco et al., 2013). We have recently published an article on digestive symptoms, insomnia and diet in on digestive symptoms among airline pilots (Lindgren et al., 2012). Moreover, we found one study investigating gastrointestinal symptoms in crew members and ground based administrative workers, showing that flying staff had more dyspeptic symptoms than ground staff (Enck et al., 1995). However, to our knowledge there are no previous publications about risk factors for digestive symptoms among different types of airline ground employees.

The aim of this study was to identify associations between digestive symptoms in airline ground employees (service agents and office workers) and selected risk factors such as gender, diet, insomnia, physical activity, BMI, type of occupation, years of employment, and to compare prevalence of digestive symptoms in service agents versus office workers from the same airline company.

\section{Material and Methods}

\subsection{Study Populations}

A self-administered standardized questionnaire was mailed to all Stockholm-based ground employees on duty in a Scandinavian airline company, 450 service agents and 1007 office workers from the same airline company. The questionnaire was based on validated questions used in previous studies. The study was approved by the regional ethical board of Uppsala University Sweden, and all participants gave their informed consent.

\subsection{Digestive Symptoms}

There were six questions on digestive symptoms: poor appetite, heartburn, diarrhea, bloating, epigastralgia and constipation, used in previous studies (e.g. Lindgren et al., 2012). Four alternatives were provided for each type of symptom: How often during the last three months have you suffered from the following digestive symptoms (often, sometimes, seldom, never). The prevalence of each digestive symptom was calculated, and then coded as often or sometimes $=1$ and seldom or never $=0$.

\subsection{Personal Factors and Diet}

Information on age, gender, smoking habits, weight, height, physical activity, and year of employment were obtained from the questionnaires. Physical activity was assessed by one question on the frequency of exercise, at least 30 minutes per session, during the last week and was scored as often $=3$, sometimes $=2$, seldom $=1$, and never $=0$. Body mass index (BMI) was calculated from the subjects' self-reported height and weight (World Health Organization 2003). There were nine questions on the frequency of consumption of certain food items (meat, fish, fruit, vegetables, egg, yoghurt, fast food, fruit juices, and fresh milk) used in previous studies (e.g. Lindgren et al., 2012). Four alternatives were given for each type of food item: How often do you consume the following food products (score $0-3$ ): never consumed $=0$, seldom $=1$, more than once a week $=2$, and daily $=3$. The food frequency questionnaire was adapted from a previous study (Takaoka and Norback 2008), with some modification of the type of food items included.

\subsection{Insomnia}

Three questions on sleep disturbance were included in the questionnaire, adapted from a previous sleep quality 
questionnaire (Akerstedt 1984). The questions covered difficulty in falling asleep at night (DIS), waking up repeatedly during the night (DMS), and waking up too early and having difficulty in getting to sleep again (EMA) (Janson et al., 2005). For all three symptoms, the subjects were asked to estimate the frequency during the last three months on a score: Most of the time $=4$, sometimes $=3$, seldom $=2$ and never $=1$. Insomnia was defined as reporting at least one of the three symptoms, most of the time or sometimes.

\subsection{Statistical Methods}

Chi-square was used to compare the prevalence of different items between service agents versus office workers. Student's t-test was used to study differences between groups for age, years of employment, and. Insomnia variables as well as digestive symptoms had four alternatives, and were dichotomized coding "most of the time" and "sometimes" as 1 and "seldom" or "never" as 0. Physical activity had four alternatives, and was dichotomized coding "sometimes" or" once a week" as 0 and "2-4 times" or "more than five times per week" as 1. The food frequency questions had four alternatives, and were dichotomized coding "never" or "seldom" as 0 and "often" or "daily" as 1.

The associations between different personal factors, food consumption and digestive symptoms were analyzed by multiple logistic regressions with Statistical Package for Social Sciences (SPSS Statistics 17.0). The questions on digestive symptoms was dichotomized as often or sometimes $=1$ and seldom or never $=0$. The OR for years of employment and age was calculated per year, and the OR for BMI was calculated for one unit of BMI.

First, all ground employed were grouped together, adjusting for possible confounding of age, gender, current smoking, physical activity, BMI, insomnia, and years employed at the airline company (mutual adjustment). Then two separate models were used, one for service agents and one for office workers, to study the association between insomnia and digestive symptoms, adjusting for the same confounders. Then we proceeded with statistical analysis within the ground employee group. We studied associations between the six digestive symptoms as dependent variables, and different food items, as independent variables, and, which were adjusted for four possible confounding variables: age, gender, current smoking and BMI (mutual adjustment).

Then we studied associations between dietary symptoms and factors other than diet. The eight independent factors included in the models were age, gender, current smoking, physical activity, BMI, insomnia, type of occupation and years employed at the airline company (mutual adjustment). One model was created for each type of digestive symptom.

Finally, all dependent variable from the previous models were entered and removed through backward stepwise regression. Results between the different types of models were compared. For all models, odds ratios (OR) with $95 \%$ confidence interval (CI) were calculated, and $\mathrm{p}<0.05$ was used as significance level (2-tailed tests).

\section{Results}

\subsection{Population Characteristics}

A total of 201 out of 450 service agents (47 men and 142 women) with an age range of 21 to 67 years participated (42\% participation rate). A total of 564 out of 1007 office workers (331men and 233 women) with an age range of 23 to 66 years participated (59\% participation rate). In total, $96 \%$ of the participating service agents and $17 \%$ of the office workers were shift-workers. Since potential determinants for digestive symptoms could differ between service agents $(n=201)$, and office workers $(n=564)$, these groups were initially compared. Service agents were more often females $(\mathrm{p}<0.001)$ but there were no difference in BMI or smoking. Totally, $44 \%$ of the total material of ground employees $(n=765)$ were overweight (BMI 25.0-30) and $8 \%$ were obese (BMI $\geqq$ 30). There were no significant differences between service agents and office workers with respect to age or years of employment, (Table 1). Age and years as active service agent was relatively closely correlated (Spearman $\mathrm{r}=0.76$ ) and age and number of years working as office worker was also relatively closely correlated (Spearman $\mathrm{r}=0.77$ ).

\subsection{Insomnia and Digestive Functional Symptoms}

When comparing insomnia symptoms between service agents and office workers, service agents reported more often difficulty inducing sleep (DIS) $(\mathrm{p}<0.001)$, waking up repeatedly during the night (DMS) $(\mathrm{p}=0.001)$, waking up to early (EMA) $(p<0.001)$ and more insomnia, a combination of the three variables $(p<0.001)$. When comparing digestive functional symptoms between service agents and office workers, service agents reported more often poor appetite $(\mathrm{p}=0.002)$, bloating $(\mathrm{p}=0.007)$ and constipation $(\mathrm{p}=0.001)$ (Table 2$)$. 
Table 1. Characteristics of the study populations (service agents and office workers)

\begin{tabular}{lcccc}
\hline & $\begin{array}{c}\text { Service agents } \\
(\mathbf{n}=\mathbf{2 0 1})\end{array}$ & $\begin{array}{c}\text { Office workers } \\
(\mathbf{n}=\mathbf{5 6 4})\end{array}$ & $\begin{array}{c}\text { Total } \\
(\mathbf{n}=\mathbf{7 6 5})\end{array}$ & \multirow{2}{*}{ p-value $^{\mathbf{a}}$} \\
\cline { 2 - 4 } & Mean (SD) or \% & Mean (SD) or \% & Mean (SD) or \% & \\
\hline Age & $49.0(9.1)$ & $48.9(7.3)$ & $48.9(9.0)$ & NS \\
Years of employment & $22.0(9.3)$ & $22.4(11.1)$ & $22.2(11)$ & NS \\
BMI & $24.2(3.3)$ & $24.9(5.9)$ & $24.9(5.5)$ & NS \\
Female & 75.1 & 41.3 & 49.7 & $<0.001$ \\
Shift working & 95.2 & 17.2 & 35.7 & $<0.001$ \\
Current smokers & 12.8 & 10.8 & 11.5 & NS \\
Physical activity & 63.8 & 56.3 & 57.3 & $0.001^{\dagger}$ \\
\hline
\end{tabular}

a Calculated by Chi-Square test for $2 \times 2$ contingency tables.

$\dagger$ Coding: more than 2 times a week

Table 2. Prevalence of insomnia and digestive symptoms among service agents and office workers

\begin{tabular}{lcccc}
\hline & $\begin{array}{c}\text { Service agents } \\
(\mathbf{n}=\mathbf{2 0 1})\end{array}$ & $\begin{array}{c}\text { Office workers } \\
(\mathbf{n = 5 6 4 )}\end{array}$ & $\begin{array}{c}\text { Total } \\
(\mathbf{n = 7 6 5 )}\end{array}$ & \multirow{2}{*}{$\mathbf{p - v a l u e}^{\mathbf{a}}$} \\
\cline { 2 - 4 } & $\%$ & $\%$ & $\%$ & \\
\hline Difficulty inducing sleep (DIS) & 55.3 & 37.7 & 42.1 & $0.000^{\#}$ \\
Waking up repeatedly during the night (DMS) & 59.1 & 41.8 & 46.2 & $0.001^{\#}$ \\
Waking up too early and having difficulty in & 59.9 & 43 & 47.3 & $0.000^{\#}$ \\
getting to sleep again (EMA) & 77.7 & 63.1 & 67 & $0.000^{\#}$ \\
Insomnia* & 13.8 & 5.8 & 8.5 & $0.002^{0}$ \\
Poor appetite & 17.5 & 13.6 & 15 & $\mathrm{NS}^{0}$ \\
Heartburn & 14.1 & 10.1 & 11.7 & $\mathrm{NS}^{0}$ \\
Diarrhea & 51.7 & 40.1 & 43.4 & $0.007^{0}$ \\
Bloating & 18.8 & 9.6 & 11.6 & $0.001^{0}$ \\
Constipation & 15.4 & 11 & 12.1 & $\mathrm{NS}^{0}$ \\
Epigastralgia & & & & \\
\hline
\end{tabular}

${ }^{\mathrm{a}}$ Calculated by Chi-Square test for $2 \times 2$ contingency tables

*Insomnia was defined as reporting at least one of the three sleepiness symptoms (DIS, DMS, and EMA)

$\mathrm{NS}=$ No significance

${ }^{\#}$ Coding: most of the time $=1$ and sometimes, seldom or never $=0$

${ }^{\circ}$ Coding: often or sometimes $=1$ and seldom or never $=0$

\subsection{Dietary Habits}

In the total material of ground employees $(\mathrm{n}=765)$, the major consumption of food products was vegetables, fruits, meat, and yoghurt. Less common were the consumption of milk, juice, fish, egg, and fast food. There were some differences in dietary habits between service agents and office workers: when the food frequency questions were coded as a $0 / 1$ variable (more or less than once a week), service agents ate more eggs $(p=0.002)$, yoghurt $(\mathrm{p}=0.001)$ and less meat $(\mathrm{p}=0.013)($ Table 3$)$. 
Table 3. Consumption of different types of food products among service agents and office workers $(n=765)$

\begin{tabular}{lllll}
\hline \multirow{2}{*}{ Type of food products } & \multicolumn{3}{l}{ How often (on average) do you consume the following food? } \\
\cline { 2 - 5 } & \multicolumn{2}{l}{ Frequency of consumption \% } & & \multicolumn{1}{l}{ Total (N=765) } \\
\cline { 2 - 4 } & \multicolumn{2}{l}{ Service agents (N=201) } & Office workers (N=564) & P-value \\
\cline { 2 - 5 } & More than once a week & More than once a week & More than once a week & 0.013 \\
\hline Meat & 64.0 & 73.4 & 71.4 & NS \\
Fish & 36.0 & 33.5 & 33.5 & NS \\
Fruit & 70.9 & 64.7 & 65.5 & NS \\
Vegetables & 84.1 & 89.9 & 87.4 & 0.002 \\
Eggs & 49.7 & 36.3 & 39.7 & 0.001 \\
Yoghurt & 68.8 & 56.2 & 58.7 & NS \\
Fast food & 3.7 & 3.4 & 3.7 & NS \\
Juice & 28.6 & 32.3 & 31.1 & NS \\
Milk & 42.9 & 39.0 & 38.9 & \\
\hline
\end{tabular}

${ }^{\text {a }}$ Calculated by Chi-Square Test.

\# The question on food consumption was dichotomized as more than once a week or every day $=1$ and seldom or never $=0$. $\mathrm{NS}=$ No significance.

\subsection{Digestive Symptoms in Multiple Logistic Regression Models}

Initially, digestive symptoms were compared between service agents and office workers in a model including all participants $(\mathrm{N}=765)$, using multiple logistic regression analysis to adjust for possible confounders. Service agents complained more of poor appetite $(\mathrm{OR}=2.33$; 95\% CI 1.34-4.18) and more of bloating $(\mathrm{OR}=1.56 ; 95 \% \mathrm{CI}$ 1.09-2.23) than office workers. Then we performed a stratified analysis on associations between insomnia and digestive symptoms, using two different regression models, one for service agents and one for office workers. There were associations between insomnia and digestive symptoms (bloating, constipation and epigastralgia) in service agents but there were no significant associations in office workers (Table 4).

Table 4. Adjusted odds ratios (OR) with $95 \%$ confidence interval $(95 \% \mathrm{CI})$ for associations between digestive symptoms and insomnia in service agents $(n=201)$ and office workers $(n=564)$

\begin{tabular}{|c|c|c|c|c|}
\hline \multirow[t]{2}{*}{ Selected item } & $\begin{array}{l}\text { Service agents vs. Office } \\
\text { workers } \dagger\end{array}$ & $\begin{array}{l}\text { Insomnia } \\
\text { Service agents }\end{array}$ & $\begin{array}{l}\text { Insomnia } \\
\text { Office workers }\end{array}$ & \# \\
\hline & $\mathrm{OR}(95 \% \mathrm{CI})$ & $\mathrm{OR}(95 \% \mathrm{CI})$ & $\mathrm{OR}(95 \% \mathrm{CI})$ & \\
\hline $\begin{array}{l}\text { Poor } \\
\text { appetite }\end{array}$ & $2.33(1.30-4.18)^{* *}$ & $3.76(0.82-17.3)$ & $1.61(0.72-3.59)$ & \\
\hline Heartburn & $1.29(0.80-2.08)$ & $3.40(0.94-12.3)$ & $1.21(0.70-2.08)$ & \\
\hline Diarrhea & $1.17(0.69-1.99)$ & $3.97(0.87-18.1)$ & $1.25(0.67-2.31)$ & \\
\hline Bloating & $1.56(1.09-2.23)^{*}$ & $2.39(1.14-5.00)^{*}$ & $0.96(0.66-1.39)$ & \\
\hline Constipation & $1.48(0.91-2.40)$ & $4.18(1.18-14.8)^{*}$ & $1.45(0.75-2.80)$ & \\
\hline Epigastralgia & $1.01(0.61-1.67)$ & $4.86(1.08 .21-9)^{*}$ & $1.74(0.94-3.22)$ & \\
\hline
\end{tabular}

$* p<0.05, * * p<0.01$

Frequency of digestive symptoms are dichotomized, defined as often or sometimes $=1$ and seldom or never $=0$.

${ }^{\dagger}$ Calculated by multiple logistic regression analysis combining service agents and office workers in one model, adjusting for age, gender, current smoking, physical activity, BMI, insomnia, and years as active commercial pilot or years as office workers in the model (mutual adjustment).

${ }^{\#}$ Calculated by multiple logistic regression analysis keeping age, gender, current smoking, physical activity, BMI, insomnia, and years as service agents or years as office workers in the model (mutual adjustment). 
Then we analyzed associations between dietary factors and digestive symptoms in the total material, adjusting for dietary factors, age, gender, current smoking, and BMI (mutual adjustment). Ground employees who consumed fast food more than once per week had more often bloating $(\mathrm{OR}=2.20 ; 95 \%$ CI 1.01-4.77) $(\mathrm{p}<0.05)$ and heartburn $(\mathrm{OR}=3.53 ; 95 \% \mathrm{CI} 1.53-8.15)(\mathrm{p}<0.01)$. Ground employees who consumed vegetables more than once per week complained less of heartburn $(\mathrm{OR}=0.52 ; 95 \%$ CI $0.28-0.95)(\mathrm{p}<0.05)$. Then we analyzed associations for other factors than diet in the total material of ground employees. Insomnia was associated with all types of digestive symptoms. Those with longer employment time had less bloating, diarrhea and heartburn. Females had more often constipation and epigastralgia, and older subjects had more often heartburn and bloating. Current smokers had more often poor appetite, heartburn and epigastralgia but had less constipation, and those with a higher BMI had more often diarrhea (Tables 5-6).

Table 5. Adjusted odds ratios (OR) with $95 \%$ confidence interval $(95 \% \mathrm{CI})$ for associations between poor appetite, heartburn and diarrhea and selected risk factors in the total material of ground employees $(n=765)$

\begin{tabular}{llll}
\hline & $\begin{array}{l}\text { Poor appetite } \\
\text { OR }(95 \% \mathrm{CI})\end{array}$ & $\begin{array}{l}\text { Heartburn } \\
\text { OR }(95 \% \mathrm{CI})\end{array}$ & $\begin{array}{l}\text { Diarrhea } \\
\text { OR }(95 \% \mathrm{CI})\end{array}$ \\
\hline Years of employments & $0.90(0.58-1.39)$ & $0.70(0.052-0.96)^{*}$ & $0.69(0.49-0.97)^{*}$ \\
Insomnia & $2.49(1.23-5.06)^{* *}$ & $2.14(1.30-3.53)^{* *}$ & $3.62(1.91-6.85)^{* * *}$ \\
BMI & $1.03(1.00-1.07)$ & $1.04(1.00-1.08)$ & $1.11(1.04-1.18)^{* *}$ \\
Female & $0.96(0.54-1.70)$ & $1.13(0.73-1.75)$ & $1.23(0.75-2.02)$ \\
Age & $0.87(0.54-1.39)$ & $1.62(1.13-2.31)^{* *}$ & $1.19(0.80-1.75)$ \\
Current smokers & $3.00(1.63-5.52)^{* * *}$ & $1.76(1.03-3.03)^{*}$ & $1.31(0.69-2.49)$ \\
\hline
\end{tabular}

${ }^{*} p<0.05,{ }^{* *} p<0.01,{ }^{* * *} p<0.001$.

Calculated by multiple logistic regression analysis keeping all 8 selected independent variables in the models (mutual adjustment).

Frequency of digestive symptoms are dichotomized, defined as often or sometimes $=1$ and seldom or never $=0$.

Table 6. Adjusted odds ratios (OR) with $95 \%$ confidence interval $(95 \% \mathrm{CI})$ for associations between bloating, constipation and epigastralgia and selected risk factors in the total material of ground employees $(n=765)$

\begin{tabular}{llll}
\hline & $\begin{array}{l}\text { Bloating } \\
\text { OR }(95 \% \mathrm{CI})\end{array}$ & $\begin{array}{l}\text { Constipation } \\
\text { OR }(95 \% \mathrm{CI})\end{array}$ & $\begin{array}{l}\text { Epigastralgia } \\
\text { OR }(95 \% \mathrm{CI})\end{array}$ \\
\hline Years of employments & $0.72(0.57-0.91)^{* *}$ & $0.85(0.60-1.19)$ & $1.01(0.71-1.45)$ \\
Insomnia & $1.62(1.8-2.22)^{* *}$ & $2.74(1.53-4.91)^{* *}$ & $3.44(1.86-6.37)^{* * *}$ \\
BMI & $1.01(0.98-1.04)$ & $0.98(0.92-1.04)$ & $1.01(0.98-1.04)$ \\
Female & $0.92(0.67-1.25)$ & $2.53(1.52-4.21)^{* * *}$ & $2.31(1.43-3.73)^{* *}$ \\
Age & $1.52(1.16-1.99)^{* *}$ & $1.24(0.83-1.84)$ & $0.85(0.57-1.27)$ \\
Current smokers & $0.85(0.55-1.33)$ & $0.41(0.17-0.98)^{*}$ & $2.19(1.24-3.87)^{* *}$ \\
\hline
\end{tabular}

${ }^{*} p<0.05,{ }^{* *} p<0.01,{ }^{* * *} p<0.001$.

Calculated by multiple logistic regression analysis keeping all 8 selected independent variables in the models (mutual adjustment).

Frequency of digestive symptoms are dichotomized, defined as often or sometimes $=1$ and seldom or never $=0$.

3.4 Digestive Symptoms in Stepwise Logistic Regression Models

As a next step, we used stepwise regression (backward elimination, Wald method) to reduce the models, including both dietary factor and other factors. Poor appetite was positively associated with current smoking $(\mathrm{p}<0.001)$, working as service agent (reference: office workers) $(\mathrm{p}=0.001)$ and insomnia $(\mathrm{p}=0.012)$ and negatively associate with frequent yogurt consumption $(\mathrm{p}=0.014)$. Heartburn was positively associated with age $(\mathrm{p}=0.001)$. Insomnia $(\mathrm{p}=0.001)$ and frequent fast food consumption $\mathrm{OR}=3.39(\mathrm{p}=0.004)$, current smoking 
$(\mathrm{p}=0.038)$ and negatively associated with years of employment $(\mathrm{p}=0.021)$ and frequent vegetables consumption ( $p=0.046)$. Diarrhea was positively associated with insomnia $(p<0.001)$, BMI $(p=0.007)$, and negatively associated with years of employment $(\mathrm{p}=0.021)$. Bloating was positively associated with age $(\mathrm{p}=0.002)$, insomnia $(\mathrm{p}=0.003)$, working as service agent $(\mathrm{p}=0.025)$ and negatively associated with years of employment $(p=0.008)$. Constipation was positively associated with female gender $(p<0.001)$, insomnia $(p<0.001)$ and negatively associated with current smoking $(\mathrm{p}=0.044)$. Epigastralgia was positively associated with insomnia $(\mathrm{p}<0.001)$, female gender $(\mathrm{p}<0.001)$ and current smoking $(\mathrm{p}=0.006)$ (Table 7).

Table 7. Significant variables identified in reduced multiple models, obtained by backward stepwise regression among the total material of ground employees $(n=765)$ (inclusion criteria $\mathrm{p}<0.1)$.

\begin{tabular}{|c|c|c|}
\hline & OR $(95 \%$ CI $)$ & $P$-value \\
\hline \multicolumn{3}{|l|}{ Poor appetite } \\
\hline Current smokers & $3.04(1.66-5.55)$ & $<0.001$ \\
\hline Service agents & $2.56(1.46-4.47)$ & 0.001 \\
\hline Insomnia & $2.47(1.22-5.00)$ & 0.012 \\
\hline Yogurt & $0.51(0.30-0.87)$ & 0.014 \\
\hline \multicolumn{3}{|l|}{ Heartburn } \\
\hline Age & $1.06(1.02-1.10)$ & 0.001 \\
\hline Insomnia & $2.25(1.37-3.72)$ & 0.001 \\
\hline Fast Food & $3.39(1.49-7.69)$ & 0.004 \\
\hline Years of employment & $0.96(0.94-0.99)$ & 0.021 \\
\hline Current smokers & $1.78(1.03-3.06)$ & 0.038 \\
\hline Vegetables & $0.57(0.33-0.99)$ & 0.046 \\
\hline \multicolumn{3}{|l|}{ Diarrhea } \\
\hline Insomnia & $3.61(1.92-6.79)$ & $<0.001$ \\
\hline BMI & $1.09(1.02-1.16)$ & 0.007 \\
\hline Years of employment & $0.98(0.95-1.00)$ & 0.021 \\
\hline \multicolumn{3}{|l|}{ Bloating } \\
\hline Age & $1.04(1.02-1.07)$ & 0.002 \\
\hline Years of employment & $0.97(0.95-0.99)$ & 0.008 \\
\hline Insomnia & $1.61(1.18-2.21)$ & 0.003 \\
\hline Service agents & $1.47(1.05-2.07)$ & 0.025 \\
\hline \multicolumn{3}{|l|}{ Constipation } \\
\hline Female & $2.97(1.85-4.75)$ & $<0.001$ \\
\hline Insomnia & $2.82(1.58-5.05)$ & $<0.001$ \\
\hline Current smokers & $0.41(0.17-0.98)$ & 0.044 \\
\hline \multicolumn{3}{|l|}{ Epigastralgia } \\
\hline Insomnia & $3.36(1.83-6.89)$ & $<0.001$ \\
\hline Female & $2.27(1.45-3.56)$ & $<0.001$ \\
\hline Current smokers & $2.18(1.25-3.80)$ & 0.006 \\
\hline
\end{tabular}

\subsection{Digestive Symptoms and Shift Work}

Finally, we analyzed the associations between shift work and digestive symptoms. Since almost all service agents were shift workers, the effect of shift work could not be investigated in this group. However, since one fifth of the office workers had shift work, the effect of shift work could be investigated in this group. We used stepwise regression (backward elimination, Wald method) including both dietary factors and other factors (same variables as in table 7), adding information on shift work and restricting the analysis to the office workers. We found no significant association between shift work among the office workers and any digestive symptom. 


\section{Discussion}

Service agents had more often bloating and poor appetite than office workers from the same airline company. Insomnia was the main predictor of digestive symptoms among service agents and strongly associated with all many types of digestive symptoms among service agents, while no associations between insomnia and digestive symptoms were found among office workers. In addition, in the total material of ground employees: vegetables, fast food, female, age, current smoking, and high BMI was associated with digestive symptoms. To our knowledge, there are no previous studies published on digestive symptoms, insomnia and diet among airline ground employees.

One advantage of the study was that it covered different age groups and that service agents were compared with office workers from the same company. However, since age and years employed as service agents or office workers at the company was closely correlated, it is difficult to separate age effects from long term effects of working. The study included one airline ground employees at Arlanda Airport in Stockholm, and the response rate was $42 \%$ among service agents and $59 \%$ among office workers. Selection bias could appear as participation rates differed between the two groups, and was relatively low. However, there were no differences in mean age, years of employment, and BMI or smoking habits between the two groups. There were differences in proportion of females and physical activity between service agents and office workers, but we adjusted for these factors in the regression models. Different statistical models were applied but the results were generally consistent. However, one limitation of the study was the cross-sectional design which rendered it difficult to draw clear conclusions on causal relationships.

Digestive symptoms were more common in service agents. Bloating and heartburn was the most common digestive symptom in both groups. In the total material of ground employees digestive symptoms were related to insomnia, female gender, and life style factors such as smoking, BMI, and frequent fast food consumption. Digestive symptoms can reduce quality of life. There is a possible role of overweight on digestive symptoms in ground employees with BMI over $25 \mathrm{~kg} / \mathrm{m}^{2}$, which is the definition of being overweight (World Health Organization 2003). In this study, $43.3 \%$ of ground employees were overweight (BMI 25.0-30) and 7.9\% were obese (BMI > 30). The mean BMI was 25.9 in males and 24.0 in females and was, nearly similar to the general Swedish population with mean BMI (Kark et al., 2005). BMI was related to diarrhea in ground employees, as reported in a previous study (Eslick, 2012).

Insomnia was defined as either most of the time having difficulty inducing sleep, waking up repeatedly, or waking up too early. Service agents reported more insomnia than office workers, possible because of the shift work. Insomnia was a strong predictor of many types of digestive symptoms among ground employees, with ORs ranging from 1.6 to 3.6 in the total material. In a stratified analysis, there were associations between insomnia, poor appetite and bloating among service agents, while there were no associations between insomnia and digestive symptoms among the office workers. This indicates that service agents are reacting more strongly with some digestive symptom if they have insomnia, possibly because of the work schedules or other stress factors related to their work. We found no previous studies on associations between insomnia and digestive symptoms in airline ground employees, but an association between shift work, causing sleep disruption, and digestive symptoms has been reported (Akerstedt, 1984). However, in a review of 20 shift work studies only four studies revealed an association between digestive symptoms and shift work (Knutsson \& Boggild, 2010). Psychosocial work conditions is another factor that could cause sleep disturbance and an association between lack of social support and sleep disturbance is previously reported in a Stockholm among commercial pilots (Runeson et al., 2010). Unfortunately we have no data on the psychosocial work environment in this study.

Females had more often constipation and epigastria than men in our study. The gender difference for constipation is in agreement with our previous study in pilots from the same company (Lindgren et al., 2012). Older subjects had more often heartburn and bloating while those with longer employment time had less heartburn, diarrhea and bloating. This indicates that aging may increase the prevalence of some digestive symptoms. However, the lower prevalence of digestive symptoms among those with long employment time indicate a possible adaptation or selection effect. Tobacco smoking was related to poor appetite, heartburn, and epigastralgia, in ground employees, which is in agreement with another study (Fujiwara et al., 2011). In contrast tobacco smoking was related to less constipation. This is different from our previous study in pilots where smokers reported more constipation (Lindgren et al., 2012). The prevalence of current tobacco smoking was $12.8 \%$ in the service agents and $10.8 \%$ in office workers, which was lower than the average smoking frequency (16\%) in the Swedish population (The Swedish National Institute of Public Health, 2008).

We found some associations between dietary habits and digestive symptoms. Frequent consumption of fast food 
was associated with more heartburn and bloating, while consumption of vegetables was associated with less heartburn. Only $3.5 \%$ of the ground employees consumed fast food more than once a week. Among the general Swedish population, 10\% consume fast food daily (Westling, 2008) and daily consumption of fast food in the USA is $37 \%$ (Paeratakul et al., 2003). Fast food, overeating, and busy schedules may cause heartburn or indigestion (Frost-Rude, 1999). In our previous study on digestive symptoms in pilots from the same airline company, frequent fast food consumption was associated with diarrhea, but not heartburn or bloating, in one of the statistical models (Lindgren et al., 2012). The consistent association between fast food consumption and digestive symptoms among ground employees in our study deserves further attention.

\section{Conclusions}

Insomnia and some digestive symptoms were more common among service agents than office workers from the same airline company. An association between insomnia and digestive symptoms was found among the service agents but not among the office workers. Moreover, insomnia, high BMI, smoking, age, female gender, and frequent fast food consumption can be associated with digestive symptoms. The lower prevalence of digestive symptoms among those with long employment time indicates a possible adaptation or selection effect. The strong association of digestive symptoms with insomnia suggests a stress component related to this occupation.

\section{Acknowledgements}

We are grateful to all of the ground staff who took part and to the Scandinavian Airline System (SAS) airline company for their cooperation. The study was financially supported by faculty resources from the Department of Medical Sciences, Occupational and Environmental Medicine, Uppsala University Hospital. We declare that we have no conflicts of interest.

\section{Conflict of Interest}

The authors declare that there is no conflict of interests regarding the publication of this paper.

\section{References}

Akerstedt, T. (1984). Work schedules and sleep. Experientia, 40, 417-422. http://dx.doi.org/10.1007/BF01952374

Campbell, A. K., Matthews, S. B., Vassel, N., Cox, C. D., Naseem, R., Chaichi, J., ... Wann, K. T. (2010). Bacterial metabolic 'toxins': A new mechanism for lactose and food intolerance, and irritable bowel syndrome. Toxicology, 278, 268-276. http://dx.doi.org/10.1016/j.tox.2010.09.001

Ehinger, C. (2013a). Stomache pain (Epigastralgia). The Stockholm Health Care Guide (Vårdguiden) Stockholm County Council (In Swedish). Retrieved from http://www.1177.se/Fakta-och-rad/Sjukdomar/Ont-i-magen/

Ehinger, C. (2013b). Constipation. The Stockholm Health Care Guide (Vårdguiden) Stockholm County Council (In Swedish). Retrieved from http://www.1177.se/Fakta-och-rad/Sjukdomar/Forstoppning/

Ehinger, C. (2013c). Flatulence. The Stockholm Health Care Guide (Vårdguiden) Stockholm County Council (In Swedish). Retrieved from http://www.1177.se/Fakta-och-rad/Sjukdomar/Gasbesvar/

Ehinger, C. (2014). Heartburn. The Stockholm Health Care Guide (Vårdguiden) Stockholm County Council (In Swedish). Retrieved from http://www.1177.se/Fakta-och-rad/Sjukdomar/Halsbranna---magsaftsreflux-/

Enck, P., Müller-Sacks, E., Holtmann, G., \& Wegmann, H. (1995). Gastrointestinal problems in airline crew members. Z Gastroenterol, 33, 513-516. http://dx.doi.org/10.1055/s-00000094

Eslick, G. D. (2012). Gastrointestinal symptoms and obesity: A meta-analysis. Obes Rev, 13, 469-479. http://dx.doi.org/10.1111/j.1467-789X.2011.00969.x.

Fisher, B. L., Pennathur, A., Mutnick, J. L., \& Little, A. G. (1999). Obesity correlates with gastroesophageal reflux. Dig Dis Sci, 44, 2290-2294. http://dx.doi.org/10.1023/A:1026617106755

Frexinos, J., Denis, P., Allemand, H., Allouche, S., Los, F., \& Bonnelye, G. (1998). Descriptive study of digestive functional symptoms in the French general population. Gastroenterol Clin Biol, 22, 785-791. http://dx.doi.org/GCB-11-1998-22-10-0399-8320-101019-ART94

Froom, P., Cline, B., \& Ribak, J. (1996). Disease evaluated on return-to-work examinations: aviation ground personnel compared to other workers. Aviat Space Environ Med, 67, 361-363.

Frost-Rude, J. (1999). Gastroesophageal reflux disease. Home Care Provid, 4, 110-113. http://dx.doi.org/10.1016/S1084-628X(99)90069-2

Fujiwara, Y., Kubo, M., Kohata, Y., Machida, H., Okazaki, H., Yamagami, H., ... Arakawa, T. (2011). Cigarette 
smoking and its association with overlapping gastroesophageal reflux disease, functional dyspepsia, or irritable bowel syndrome. Intern Med, 50, 2443-2447. http://dx.doi.org/10.2169/internalmedicine.50.6012

Huerta-Franco, M. R., Vargas-Luna, M., Tienda, P., Delgadillo-Holtfort, I., Balleza-Ordaz, M., \& Flores-Hernandez, C. (2013). Effects of occupational stress on the gastrointestinal tract. World $J$ Gastrointest Pathophysiol, 4, 108-118. http://dx.doi.org/10.4291/wjgp.v4.i4.108

Janson, C., Norbäck, D., Omenaas, E., Gislason, T., Nyström, L., Jõgi, R., ... RHINE study group. (2005) Insomnia is more common among subjects living in damp buildings. Occup Environ Med, 62, 113-118. http://dx.doi.org/10.1136/oem.2003.011379

Kark, M., Tynelius, P., \& Rasmussen, F. (2007). Overweight and obesity in a population perspective. Department of Public Health Science, Karolinska Institute, Stockholm, Sweden (in Swedish). Retrieved from http://dok.slso.sll.se/CES/FHG/Folkhalsoarbete/Rapporter/del6_overvikt_web.pdf

Knutsson, A., \& Boggild, H. (2010). Gastrointestinal disorders among shift workers. Scand J Work Environ Health, 36, 85-95. http://dx.doi.org/10.5271/sjweh.2897

Lindgren, T., Runeson, R., Wahlstedt, K., Wieslander, G., \& Dammström, B. (2012). Digestive functional symptoms among Commercial Pilots: in relation to diet, insomnia and lifestyle factors. Aviat Space Environ Med, 83, 872-878. http://dx.doi.org/10.3357/ASEM.3309.2012

Paeratakul, S., Ferdinand, D. P., Champagne, C. M., Ryan, D. H., \& Bray, G. A. (2003). Fast-food consumption among US adults and children: dietary and nutrient intake profile. $J$ Am Diet Assoc, 103, 1332-1338. http://dx.doi.org/10.1016/S0002-8223(03)01086-1

Pierson, K., Power, Y., Marcus, A., \& Dahlberg, A. (2007). Airline passenger misconduct. Management implications for physicians. Aviat Space Environ Med, 78, 361-367. http://www.asma.org/journal

Ribak, J., Cline, B. V., \& Froom, P. (1995). Common accidents among airport ground personnel. Aviat Space Environ Med, 66, 1188-1190.

Runeson, R., Lindgren, T., \& Wahlstedt, K. (2010). Sleep problems and psychosocial work environment among Swedish commercial pilots. Am J Ind Med, 54, 545-551. http://dx.doi.org/10.1002/ajim.20822

Schöldeen, Å. (2015). Diarrhea and vomiting. The Stockholm Health Care Guide (Vårdguiden) Stockholm County Council (In Swedish). Retrieved http://www.1177.se/Fakta-och-rad/Sjukdomar/Magsjuka---diarre-och-krakningar/

Takaoka, M., \& Norbäck, D. (2008). Diet among Japanese female university students and asthmatic symptoms, infections, pollen and furry pet allergy. Respir Med, 102, 1045-1054. http://dx.doi.org/10.1016/j.rmed.2008.01.023

The Swedish National Institute of Public Health. (2008). Life style report 2008 (In Swedish). Vol 2008:5. http://www.folkhalsomyndigheten.se/pagefiles/12271/R2009-07-Livsstilsrapport-2008.pdf

Tougas, G., Chen, Y., Hwang, P., Liu, M. M., \& Eggleston, A. (1999). Prevalence and impact of upper gastrointestinal symptoms in the Canadian population: findings from the DIGEST study. Domestic/International Gastroenterology Surveillance Study. Am J Gastroenterol, 94, 2845-2854. http://dx.doi.org/10.1111/j.1572-0241.1999.01427.x

Upham, P. (2003). Towards sustainable aviation. Earthscan Publications, London, Sterling, VA. Retrieved from http://trove.nla.gov.au/version/45396873

Westling, A. (2008). Between-meal snack habits in Sweden (In Swedish). Swedish University of Agricultural Sciences. Department of Economy, Uppsala. Retrieved from http://ex-epsilon.slu.se/2473/1/Westling_Andreas_080514.pdf

World Health Organization. (2003). Global Strategy on Diet, Physical Activity and Health. Obesity and Overweight. Retrieved from http://www.who.int/dietphysicalactivity/strategy/eb11344/en/index.htlm

\section{Copyrights}

Copyright for this article is retained by the author(s), with first publication rights granted to the journal.

This is an open-access article distributed under the terms and conditions of the Creative Commons Attribution license (http://creativecommons.org/licenses/by/3.0/). 